\title{
A Late Adopter's Perspective on Minimally Invasive Surgery - Presidential Lecture at KSEL 2018 .
}

\author{
Sun Whe Kim, M.D., Ph.D., FACS \\ Department of Surgery, Seoul National University College of Medicine, Seoul, Korea
}

\author{
Corresponding author \\ Sun Whe Kim \\ Department of Surgery, Seoul National University College of Medicine, 101 Daehak-ro, Jongno-gu, Seoul 03080, Korea \\ Tel: +82-2-2072-2315, E-mail: sunkim@snu.ac.kr \\ ORCID: http://orcid.org/0000-0001-6315-6019
}

This is an Open Access article distributed under the terms of the Creative Commons Attribution Non-Commercial License (http:// creativecommons.org/licenses/by-nc/4.0/) which permits unrestricted non-commercial use, distribution, and reproduction in any

Copyright (C) 2018 The Journal of Minimally medium, provided the original work is properly cited.

Invasive Surgery. All rights reserved.

Innovative techniques evolve over several steps; namely, awareness, interest, evaluation, trial and adoption. According to Rogers' technology adoption curve ${ }^{1}$ shown in Fig. 1, surgeons, like all other people, can be categorized as innovators, early adopters, early majority adopters, late majority adopters and laggards. Innovators simply join new technology when it is new. Early adopters join when they perceive a benefit or when there is productivity gain, while late adopters, who belong to the right side of the curve join or adopt new technology when there is plenty of help and support or when they have to. I am a late adopter, especially when it comes to minimally invasive surgery (MIS).

During the last few decades, MIS has changed the leading generation of surgeons and mainstream surgery. In addition, MIS now accounts for more surgical procedures. Many surgeons agree that transplantation surgery, extensive radical cancer surgery and MIS are the three highlights of the surgical field. Among these, MIS is rapidly growing, infiltrating and converging with other two types of surgery. For instance, in the hepatobiliary pancreatic surgery field that my major belongs to, my junior colleagues or disciples in Seoul National University Hospital (SNUH) have made great successes recently, such as pure laparoscopic living donor hepatectomy, robot hybrid pancreaticoduodenectomy (PD) and laparoscopic

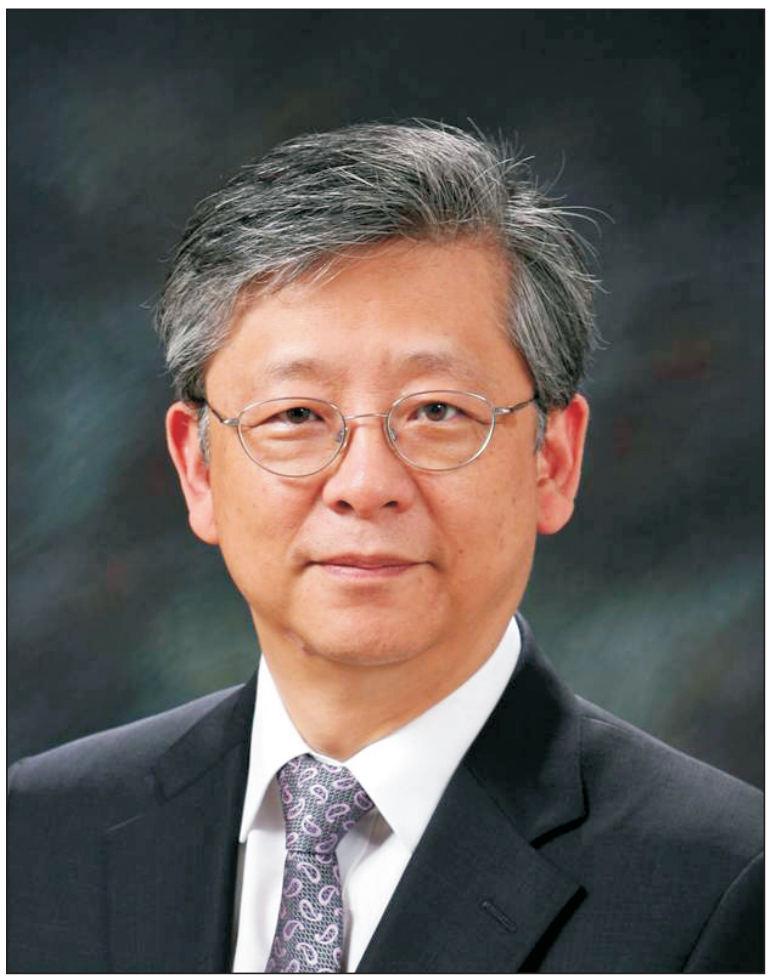

https://doi.org/10.7602/jmis.2018.21.2.52 


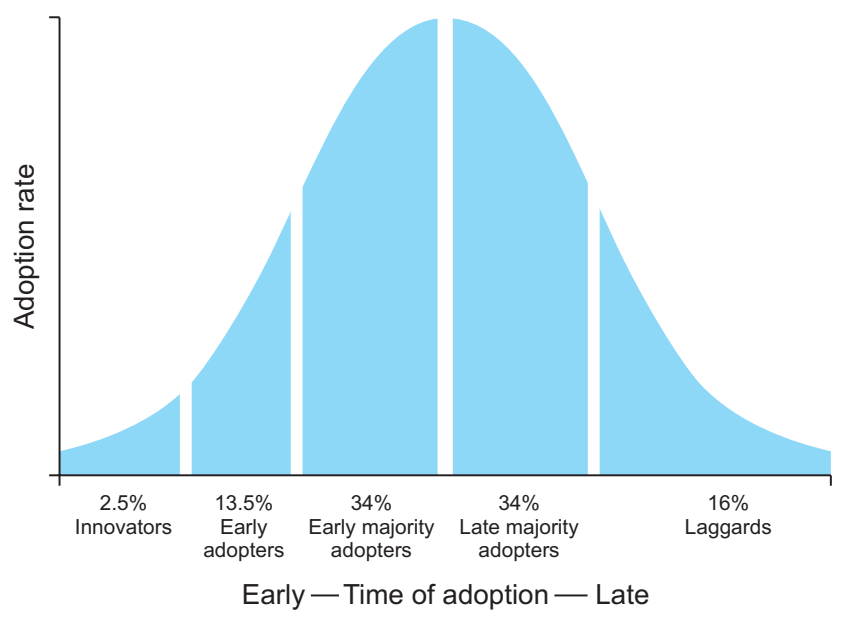

Fig. 1. Technology adoption curve (from Rogers, Everett M, 1964).

assisted hepatectomy for Klatskin tumor. However, the only MIS procedures I perform on a regular basis are laparoscopic cholecystectomy and laparoscopic distal pancreatectomy, while I do not conduct MIS for malignant disease. The surgery I perform most often is open conventional PD. Among 3,000 or so PDs ever conducted at SNUH, I personally have performed more than half of these. Therefore, I must belong to the laggard or late adopter group when it comes to MIS, especially MIS PD.

Who are 'Aggressive surgeons'? Maybe they are progressive rather than conservative. They may also want rapid rather than slow changes and prefer challenges rather than safety. In general, MIS surgeons are more aggressive than open surgeons. Although it cannot be didactic, MIS surgeons tend to be fast learners who would rather be first at something than the best at it. Accordingly, they are usually referred to as belonging to the next generation and early adopters. I cannot help calling myself a late adopter.

\section{PREDISPOSITION TO BE A LATE ADOPTER}

Why and how do people like me become late adopters? Some people are said to be late bloomers and slow learners. I was one such person when I was young. However, I had no problem like this because I knew many great scientists were slow learners such as Albert Einstein.

Obsessive persons tend to adopt a new technique later than ordinary people. Surgeons of obsessive character often think their techniques are not perfect and they are still on their learning curve, regardless of their volume of experience. Obsessive persons usually prefer monotasking to multitasking. I am that kind of surgeon; therefore, I still feel my PD technique is not perfect yet despite my great experience with the procedure. Accordingly, it is hard for me to imagine conducting PD using MIS. I think "I am bad at multitasking, but I could be amazing at monotasking."

Surgeons who depend on their hands also might have difficulty implementing MIS. This is because they use their hands to feel for pulsation, consistency, good exposure, abrupt massive bleeding control and to change the light direction so that they can see mesenteric vessels. MIS surgeons may argue about good exposure saying magnified view by laparoscope, especially for deep seated operative field.

I think claustrophobia, which is a strong fear of being in a small closed space, could be a predisposing factor. People may feel stuffy when they see a small monitor and feel like they are in a small box or tunnel. Indeed, I felt that I could not breathe enough and did not blink my eyes when conducting laparoscopic surgery.

\section{RELUCTANCE TO ADOPT MIS IN PANCREATIC SURGERY}

During the last few decades, MIS has been chasing open pancreatic surgery. This was the period when I personally developed my pancreatic surgery and gained a lot of experience. I have put too much work into developing my technique to attempt complicated MIS procedures and feel that I can conduct this surgery better than MIS surgeons. However, with regards to PD, I am still learning methods of improving the completeness of local tumor control by surgery. I think it will take me forever to become confident of every procedure used in PD. So I have asked "Can MIS surgeons achieve what I do by open surgery?"

There are many technical issues involved in pancreatic surgery, such as ensuring secure anastomosis between the pancreas and enteral tube, extended lymph node and nerve plexus dissection, combined vascular resection, artery first approach, meso-pancreas excision, radical antegrade modular pancreatosplenectomy, borderline resection of pancreatic cancer, duodenum preserving resection of the head of the pancreas (DPRHP), pancreas preserving duodenectomy, etc. All of these seem to be challenges to MIS surgeons. Can they do this by safe and radical MIS?

Since I started my career as pancreatic surgeon in early 1990s, I have been struggling with pancreatic leakage as most pancreatic surgeons do. Different techniques have been tried regarding site, mode and route. It took me more than 10 years to settle on my pancreatico-jejunostomy technique, although it is not perfect yet. I thought it would be challenging to do it by MIS. However, my junior colleague, Dr. Jang tried robotic hybrid PDs with robotic pancreaticojejunostomy using exactly the same method that I taught him and reported recently., 
Duodenal preserving resection of the pancreatic head (DPRHP) and pancreatic head resection with segmental duodenectomy were first introduced to Korea 20 years ago by myself. 4.5 Several modified techniques for DPRHP have since been reported by different surgeons, including myself. My technique was total removal of the pancreatic head while completely preserving the common bile duct and inferior pancreaticoduodenal arteries. I thought it would be impossible to do the same procedure by MIS because this procedure is rarely performed even by open surgery. Nevertheless, some centers in Asia have recently demonstrated that robotic DPRHP is feasible. $^{6}$

I also was the first to introduce pancreas-sparing duodenectomy to Korea. Specifically, I removed the entire duodenum from a patient with a large duodenal GIST located at the duodenal second portion, while completely preserving the pancreas. The postoperative long-term outcome was excellent. However, a laparoscopic procedure for this has also been recently reported. ${ }^{78}$

The artery first approach is designed to decrease the R1 rate for pancreatic cancer, especially for the one located at the uncinate process. This is another procedure, known as the SMA first approach for PD, that was first presented in Korea by myself a few years ago. Again, laparoscopic/robotic versions have since been reported.'

How about different techniques of vascular resection during PD? In 2011, Dr. Kendrick from the Mayo Clinic reported graft interposition for SMV resection by a laparoscopic technique, which has since been conducted by many others. ${ }^{10}$

Finally, lymph node and nerve plexus dissection are probably the most important aspects of local tumor control during PD. I though this would be a large hurdle for MIS; however, many MIS lymph node and nerve plexus dissections have recently been reported. In addition, many supporters appeared and eased the pressure of MIS for cancer surgery. Five recently performed randomized controlled trials, including a Korean one led by myself, ${ }^{11}$ have been performed to determine the extent of surgery needed to treat pancreatic head cancer. The results of these trials indicated that there was no need to conduct extended lymph node and nerve plexus dissection. As a result, MIS surgeons no longer need to worry about the extent of surgery.

So, is now the moment of surrender? Probably yes. I accept that it is only a matter of time. Nevertheless, I would like senior open conventional surgeons to keep some points in mind. Specifically, open conventional surgery will probably always have a place and should be an essential part of laparoscopic surgery training. In addition, it is probably time for us to consider organizing a Society of Open Surgery (SOS) for surgeons such as myself.

\section{MISSION AS PRESIDENT OF KSELS}

One might ask how I could become the President of KSELS since I am a late adopter and conservative open surgeon for. In fact, I was nominated more than three times for the Presidency by several influential persons, including former Presidents and the Chairman of the Board of Directors. It reminded me of "Calling thrice at the thatched cottage" in the Chinese history novel "The Romance of Three Kingdoms". I guess my repeated nominations were because I was thought of as a surgeon who was very much interested in education. In addition, I have published several papers and books about surgical education, including the 'Surgical Resident Education Program of Korean Surgical Society (KSS)', 'Aim of education for surgical resident', 'Aim of surgical education for medical student', 'Aim of education for hepatobiliary pancreatic surgery fellowship training, 'Study on the status and improvement of medical subspecialty training', and 'Research to establish a better subspecialty board system in Korea'. I am also the founder of the Korean Association of Surgical Education.

So, the mission I was given was to be a supporter of establishment of a MIS qualification system by KSELS, as a President specialized in surgical education and training, by leading all the subspecialty surgical societies of KSS, where I was President at that time. All of the board members of KSELS have tried to establish qualification systems through workshops and communication with leadership of surgical societies (Fig. 2). We have not yet reached a consensus, although we have made some progress. I am looking forward to seeing KSELS establish a good system in the future.

\section{ADVICE FOR FUTURE MIS SURGEONS}

I would like to give some advice to all current and future MIS surgeons by providing some messages that they should

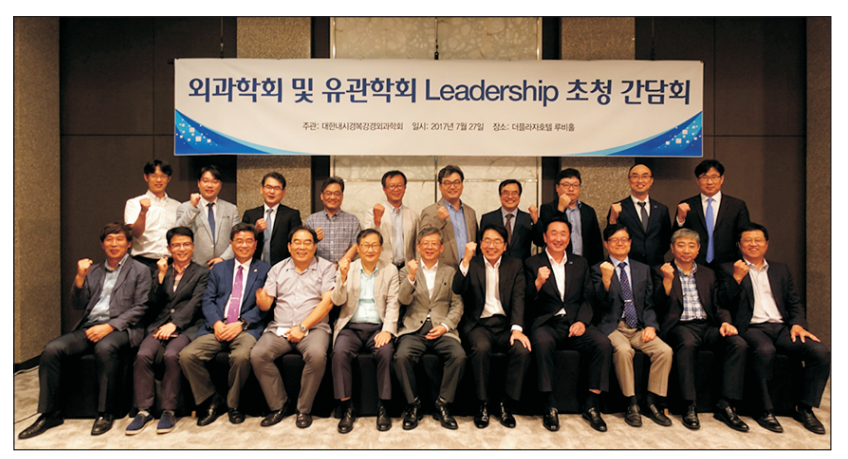

Fig. 2. KSELS invited leaders of the Korean Society of Surgery and its subspecialty surgical societies to a meeting discussing development of a MIS qualification system in Korea. 

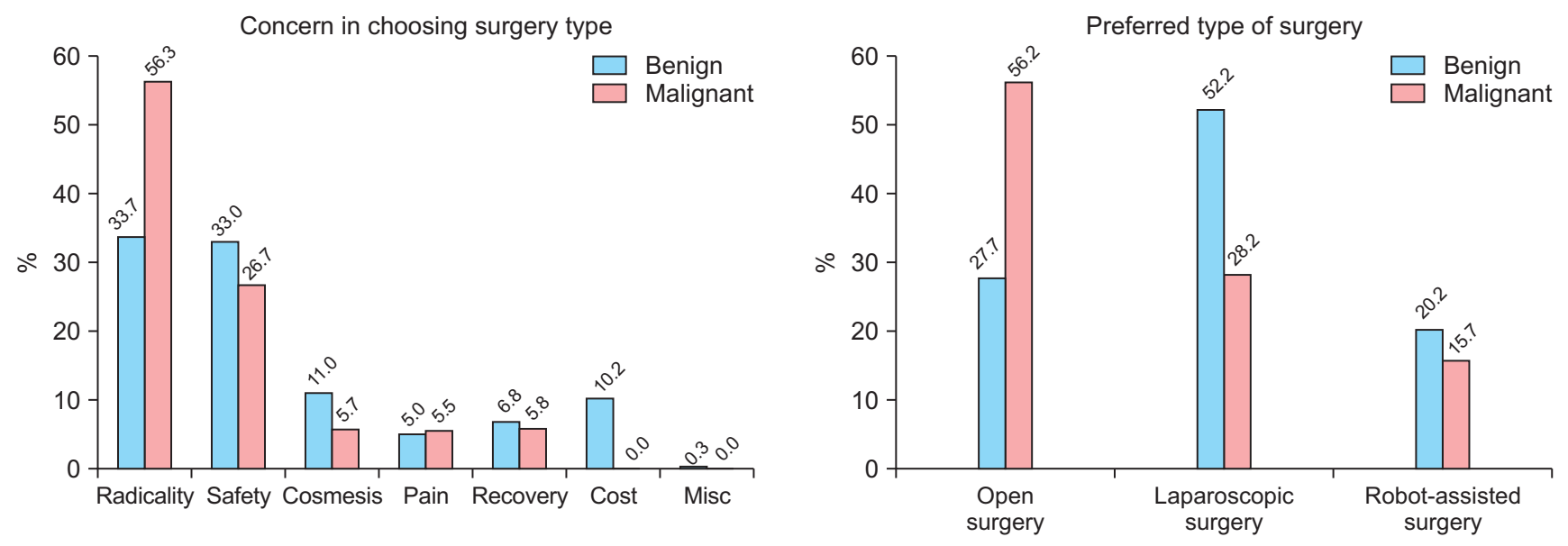

Fig. 3. People's concern in choosing type of surgery and preferred type of surgery. Radicality and safety are the two greatest concerns, regardless of the nature of disease. MIS is preferred for benign disease, but open surgery is preferred for malignant disease (Kwon et al. 2014).

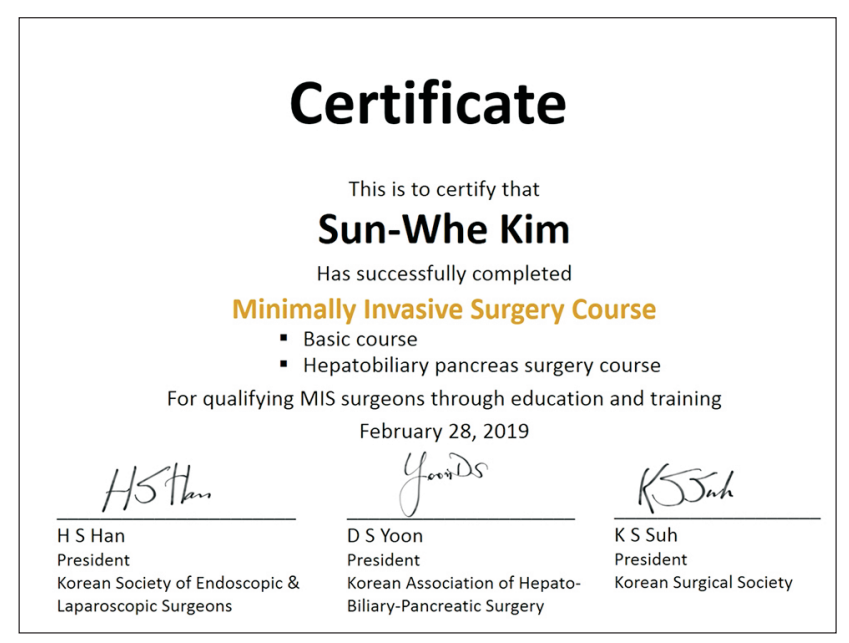

Fig. 4. Proposed sample certificate for MIS qualification. The certificate is only for completeness of the basic and subspecialty course endorsed by 3 levels of academic societies.

\section{keep in mind.}

The first is 'Patient safety first'. MIS has the potential to kill people, similar to a recent accident in which a self-driving vehicle hit and killed a bicyclist. Just because they have not yet been exposed, hidden problems may not be as rare as you expect. I accept we should move forward, as we have kept developing self-driving cars despite this accident. However, MIS surgeons should keep these words in mind, "Even a single patient sacrifice is not acceptable."

Second, it is important to keep in mind 'Radicality and curability' when conducting MIS. One of the things I am worried about is whether we are going back to technique-based surgery from science-based surgery. Science based surgery should be allowed to take every step before adoption of a new procedure; specifically, its technical feasibility should be evaluated, followed by its safety and efficacy, in series. This should be followed by reporting and registration, suggestion of indication, broadening of indication to malignant disease, evaluation of early oncologic outcome and finally evaluation of long-term oncologic outcome.

The third message is 'Respect the patient's concern and preference' when choosing the type of surgery to be used, especially for malignant disease. A recent survey report conducted by SNUH ${ }^{12}$ has shown that radicality and safety rather than cosmetics and pain are the main concerns reported by patients, and that open surgery is the preferred method for malignant cases (Fig. 3). Of course, this pattern will change. Indeed, an increasing number of patients want MIS these days, but they might have been wrongly informed by mass media or other sources. Surgeons shouldn't forget that surgery should be for patients, not for the surgeon. It may be an option between rapid evolution with significant side effects and slow evolution with minimal side effects. I always worry that the vocal minority leads this world without listening to the silent majority.

The last key point is 'Qualification'. Surgeons should be prepared and qualified before they conduct any procedures. We need a good system of qualification run by academic societies. I hope KSELS will be able to provide certificates for MIS. For instance, a certificate of completion of a MIS qualification course, basic and hepatobiliary pancreatic MIS course, endorsed by 3 levels of academic societies, KSELS, the Korean Association of HBP Surgery, and the Korean Surgical Society. The basic course is run by KSELS and advanced courses by subspecialty societies. Endorsement of the KSS is also required to raise public confidence (Fig. 4).

I conclude my presentation with the following messages. To surgeons, be modest, consider patient safety first, learn and 
get qualified before conducting procedures. To patients, claim your right to know and choose, don't rely on mass media, and think about what matters most. To KSELS, establish an education, accreditation and credentialing system. To the KSS, define standards and raise public confidence.

\section{REFERENCES}

1) Rogers EM. Diffusion of innovations. New York: Free Pr.; 1983.

2) Kim HS, Han Y, Kang JS, et al. Comparison of surgical outcomes between open and robot-assisted minimally invasive pancreaticoduodenectomy. J Hepatobiliary Pancreat Sci 2018;25:142-149.

3) Kim H, Kim JR, Han Y, Kwon W, Kim SW, Jang JY. Early experience of laparoscopic and robotic hybrid pancreaticoduodenectomy. Int J Med Robot 2017;13.

4) Kim SW, Kim KH, Jang JY, Park S, Park YH. Practical guidelines for the preservation of the pancreaticoduodenal arteries during duodenum-preserving resection of the head of the pancreas: clinical experience and a study using resected specimens from pancreaticoduodenectomy. Hepatogastroenterology 2001;48:264269.

5) Ahn YJ, Kim SW, Park YC, Jang JY, Yoon YS, Park YH. Duodenal-preserving resection of the head of the pancreas and pancreatic head resection with second-portion duodenectomy for benign lesions, low-grade malignancies, and early carcinoma involving the periampullary region. Arch Surg 2003;138:162-168; discussion
168.

6) Peng CH, Shen BY, Deng XX, Zhan Q, Han B, Li HW. Early experience for the robotic duodenum-preserving pancreatic head resection. World J Surg 2012;36:1136-1141.

7) Corcione F, Pirozzi F, Sciuto A, Galante F, Bracale U, Andreoli F. Laparoscopic pancreas-preserving subtotal duodenectomy for gastrointestinal stromal tumor. Minim Invasive Ther Allied Technol 2013;22:187-190.

8) Poves I, Burdio F, Alonso S, Seoane A, Grande L. Laparoscopic pancreas-sparing subtotal duodenectomy. Jop 2011;12:62-65.

9) Memeo R, De Blasi V, Perotto O, Mutter D, Marescaux J, Pessaux P. Robotic Lymphadenectomy During Pancreatoduodenectomy with First Superior Mesenteric Artery Dissection. Ann Surg Oncol 2016;23:968.

10) Kendrick ML, Sclabas GM. Major venous resection during total laparoscopic pancreaticoduodenectomy. HPB (Oxford) 2011;13:454-458.

11) Jang JY, Kang MJ, Heo JS, et al. A prospective randomized controlled study comparing outcomes of standard resection and extended resection, including dissection of the nerve plexus and various lymph nodes, in patients with pancreatic head cancer. Ann Surg 2014;259:656-664.

12) Kwon W, Jang JY, Park JW, Han IW, Kang MJ, Kim SW. Which method of pancreatic surgery do medical consumers prefer among open, laparoscopic, or robotic surgery? A survey. Ann Surg Treat Res 2014;86:7-15. 